\title{
Analysis of Annular Pressure Generation Mechanism and Research on Safety Evaluation
}

\author{
Yingying Zhang ${ }^{1}$, Wei Rong ${ }^{1}$, Weiyi Xie ${ }^{1}$, Qilun Liu ${ }^{1}$, Xixi Chen ${ }^{1}$, Liangwen Liu ${ }^{1}$, Xu Zhang ${ }^{1}$ \\ ${ }^{1}$ China National Petroleum Corporation North China Oilfield Branch Engineering Technology Research Institute, Renqiu Hebei, 062552
}

\begin{abstract}
With the rapid increase of seasonal heating gas consumption in winter in the Beijing-Tianjin-Hebei region, the existing gas storage scale and injection and production well network in the central Hebei region can hardly meet the demand of storage capacity utilization and gas recovery. Therefore, the effective utilization of old Wells has become the goal of gas storage construction. However, the old Wells that have been put back into production are mostly converted from depleted reservoirs, which have different degrees of annular pressure problems. Through investigation and investigation, it is found that there are many factors causing annular zoning pressure. By analyzing the properties of Wells with high sulfur content and high temperature and pressure, this paper studies the mechanism of causing annular zoning pressure, and puts forward the safety management method, so as to make the safety evaluation of annular zoning pressure more comprehensive.
\end{abstract}

\section{Introduction}

As a clean energy, natural gas is increasingly recognized by the society, and there are more and more natural gas storage facilities. Gas storage is the best choice for natural gas production peak shaving and natural gas resource storage. A prominent problem of gas storage wells is the pressure problem in the closed annulus of the production string and casing, and there are multiple sources of problems.

\subsection{Current status at home and abroad}

The U.S. Department of Mines has calculated the annulus pressure in the outer continental shelf area of the United States and found that there are about 8,000 wells in this area with one or more annulus under pressure at the same time (see Figure 1), and about $50 \%$ of the annulus pressure It occurs in the annulus between the production casing and the tubing. $10 \%$ of the annulus pressure occurs in the annulus between the intermediate casing and the production casing, and $30 \%$ of the annulus pressure occurs in the surface casing and the intermediate casing. Between the annulus ${ }^{[1-3]}$.

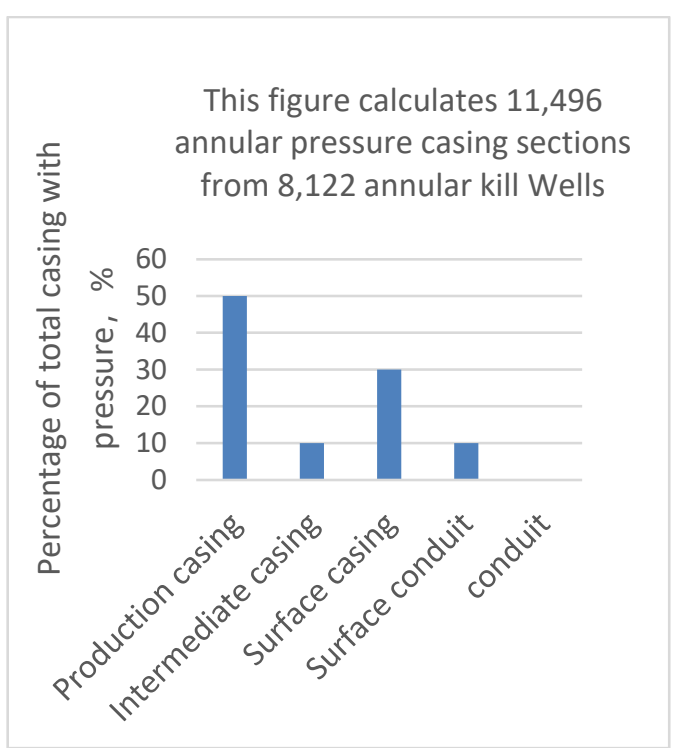

Fig.1. Statistical diagram of pressure on casings in each layer of the area

In gas fields such as Dina in China's Tarim Basin and Longgang in Sichuan Basin, the annulus pressure is an important problem that plagues the safe development of gas wells. Annulus pressure means that the wellhead annulus pressure gauge is abnormally opened. If the wellhead blowout valve is discharged and the casing annulus is closed, the pressure rises to a certain level again. It is usually called annulus pressure in the world ${ }^{[4-5]}$. The pressure in the annulus not only causes corrosive gases such as $\mathrm{CO} 2$ and $\mathrm{H} 2 \mathrm{~S}$ to enter the annulus of the oil casing to corrode the inner wall of the casing, but also causes the casing to withstand high pressure for a long time. There is 
a risk of natural gas leakage to the formation and the wellhead, and even cause Catastrophic accident ${ }^{[6]}$.

\subsection{Related concepts of annular pressure}

Generally, production wells are composed of many layers of casing, so there are several annular spaces. Depending on the location of the annulus, the annulus can be represented as "A" annulus, "B" annulus, "C annulus"... ${ }^{\text {[7- }}$ 9]. "A" annulus refers to the annulus between the tubing and the production casing, and "B" annulus refers to the annulus between the production casing and the adjacent upper layer of casing. From then on, the annulus between each layer of casing and the adjacent layer of casing is shown in alphabetical order (see Figure 2).

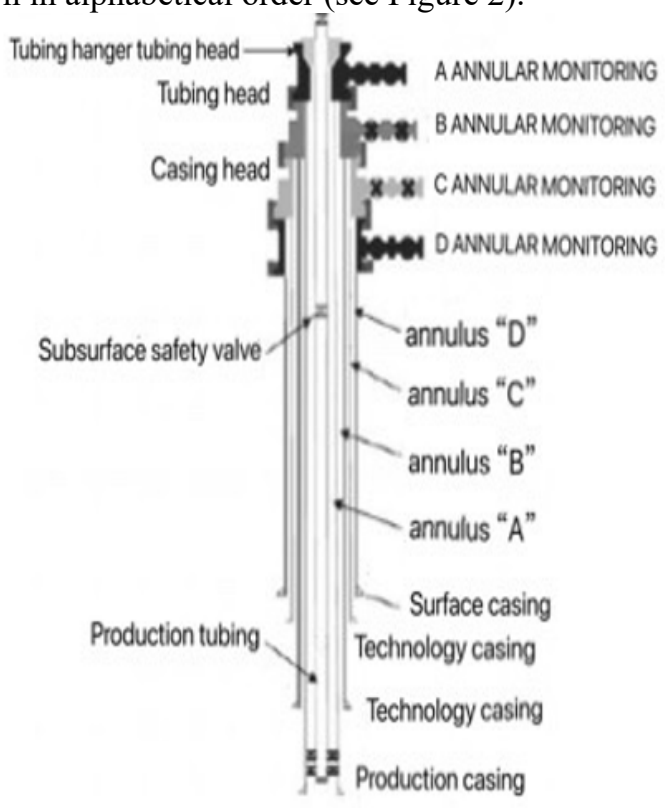

Fig.2. Schematic diagram of annulus.

Annulus under pressure refers to the abnormal opening pressure of the wellhead annulus pressure gauge. If the pressure is released through the wellhead blow-out valve, the pressure of the casing annulus blow-out valve rises again to a certain level. This situation is usually called annulus pressure in the world ${ }^{[10]}$.

\section{Annular pressure generation mechanism}

\subsection{For high-sulfur gas well analysis}

During the development of oil and gas wells, high-sulfur annulus pressure gas wells have major safety issues. Therefore, by analyzing the mechanism of killing wells in the high-sulfur annulus, safety assessments can find shortcomings and make up for the shortcomings, which can provide a reference for safe production management.

According to the production process, the generation of annulus pressure can be divided into three types of annulus pressure at the initial stage of mining, during the mining process, and when production is stopped. In the early stage of mining, there is a large temperature difference between the well and the leaked area, resulting in airflow disturbances and dynamic pressure in the wellhead; during the production process, due to the leakage of the tubing string and casing string, if the quality of the cement ring is unstable during the operation, Was destroyed, the air flow flew to the annulus, generating dynamic pressure in the wellhead annulus. Finally, abnormal production shutdown will also cause annulus pressure, including planned well killing shutdown and abnormal shut-in, which will cause sudden large fluctuations in wellbore temperature, resulting in annulus pressure, and at the same time, the pressure difference before and after shut-in. The bulging effect that causes the annulus string will also cause the annulus to become compressed.

\subsection{For high temperature and high pressure gas well analysis}

Theoretically speaking, there is a possibility that the casing and the body and the thread of the downhole tool may leak. The cement ring itself has micro-cracks, which causes the formation fluid to flow up along with the microcracks or to the formation. . In addition, as the last barrier for gas well safety, the wellhead device may also fail.

From the field practice, the annulus pressure of domestic high-temperature, high-pressure and high-acid gas wells is mainly due to the leakage of tubing and casing, and the pressure and material grades selected for the wellhead devices are high and there are fewer problems. Well barrier components with a high failure rate are mainly tubing, casing, wellhead and cementing ring. In addition, they also include downhole safety valves, packers and other components.

Therefore, the main reasons for the pressure in the annulus of a gas well are the leakage of downhole tubing and casing, wellhead leakage and cement ring leakage, which cause formation fluids to enter various annulus or escape to the ground. For the annulus killing wells in high temperature, high pressure and high acid gas fields, if they are not distinguished, workover operations are adopted, and the operating costs will be very high.

\section{Safety evaluation method}

\subsection{Calculation of the Maximum Pressure Allowable Value of Killing Wells in Annular Zone}

The maximum allowable value of annulus pressure refers to the maximum allowable working pressure limit in the closed annular space formed by pressure-bearing components such as wellhead crosses, packers, tubing and casing during the production process of a gas well. This value varies with production time and flow pressure. In different production stages, the bottom hole flow pressure is different, and the maximum pressure limit is also different, but in the short term (such as 1 month, 1 quarter), the value is relatively stable.

The maximum allowable annulus pressure value for all annulus is calculated based on the minimum material strength (such as the internal pressure and collapse strength of the casing/tubing) and the formation stress 
where the casing shoe is located. Due to the high safety risk of annulus with pressure, it is necessary to establish a "high-voltage line". Once this limit is exceeded, corresponding remedial measures must be taken, or even the well must be abandoned. Under normal circumstances, it is necessary to carry out wellhead annulus pressure safety evaluation for each high-pressure gas well. The maximum allowable wellhead pressure value is the maximum allowable working pressure value for a specific annulus, reflecting the pressure level that the annulus can withstand. The calculation model is:

The allowable pressure value determined by the internal pressure resistance of the pay zone casing:

$$
P_{A}=a P_{t n}+P_{w e}-\rho g h
$$

The allowable pressure value determined by the collapse strength of the tubing:

$$
P_{B}=a P_{y j}+P_{L}-\rho g h
$$

The allowable pressure value determined by the pressure difference level of the packer:

$$
P_{C}=a P_{f}+P_{L}-\rho g h
$$

The allowable pressure value determined by the pressure level of the casing head:

$$
P_{D}=b P_{s}
$$

Where: PA, PB, PC, PD are the allowable annulus pressure limits of each pressure-bearing component of casing, tubing, packer, and casing head (the same below); $\mathrm{a}, \mathrm{b}$ are the safety of corresponding pressure-bearing components Coefficient; Ptn is the internal pressure strength of the casing; Pyj is the tubing collapse strength; Pf is the compressive strength of the packer; Ps is the pressure strength of the casing head; Pwe is the pressure of the cement or surrounding rock outside the pipe at the sealing position, Generally, the static water column pressure is taken; PL is the flow pressure in the tubing at the sealing position; $\rho$ is the density of the annulus protection liquid; $g$ is the acceleration of gravity; $h$ is the vertical depth of the sealing position.

\subsection{Annular pressure monitoring}

To manage the annulus pressure, data on the annulus pressure must be obtained. In some high-pressure gas wells, the casing four-way bypass valve was not cleaned in time and thoroughly during the drilling and cementing process. Mud and oil well cement remained in the casing four-way bypass valve, which caused the annulus pressure to be unable to monitor and subsequent pressures. Management cannot be implemented. Ensuring the safety and reliability of the casing four-way bypass valve is a prerequisite for annulus pressure monitoring. Under normal circumstances, the annulus pressure develops from the A ring to the $\mathrm{B}, \mathrm{C}$, and $\mathrm{D}$ annulus. It is recommended to use a pressure transmitter to monitor the annulus pressure in real time in the inner annulus (A and $\mathrm{B}$ annulus). Regular monitoring can be performed using ordinary pressure gauges.

\subsection{Annular protection fluid performance maintenance}

This measure is suitable for most wells with lower annulus liquid level. When a gas well was put into production and completed, the annulus A was filled with annulus protection fluid with a $\mathrm{PH}$ value of 9.5 to 11.0 and a density of 1.25 to $1.27 \mathrm{~g} / \mathrm{cm} 3$. Annular protection solution formula: water + organic salt weighting agent + organic deoxidizer + bacteriostatic agent + corrosion inhibitor + desulfurizer + sodium hydroxide solution. During the production process, due to the leakage of acid gas, the gas and liquid inside and outside the tubing replaced each other, the annulus protection fluid was continuously neutralized, the $\mathrm{pH}$ value decreased, and the liquid level dropped. In order to maintain the alkaline conditions of the annulus protection fluid A and protect the casing head and casing, generally after the casing pressure is relieved, the annulus protection fluid is filled and supplemented in time ( $\mathrm{PH}$ value $12 \sim 13$, density $1.12 \sim 1.15 \mathrm{~g} / \mathrm{cm} 3$ ). According to the on-site measurement results, the current $\mathrm{pH}$ value of the annulus protection fluid is maintained above 9 .

\subsection{Annulus filled with nitrogen for corrosion protection}

This measure is suitable for wells with deep tubing or casing leakage and large leakage. In the early treatment of abnormal casing pressure, it has been proved that it is necessary to frequently replenish protection fluid, fill wells with large amounts of fluid, and use non-sulfurresistant material casing short sections for abnormal casing pressure during drilling and completion, and the inertness of nitrogen can be used Protect the annulus casing, casing head and other components. The limitation of this measure is that it has higher requirements for the tightness of the wellhead equipment.

The nitrogen filling effect is better, the liquid nitrogen is easy to obtain and transport, the operation cost is low, and there is no pollution. Theoretically, under the conditions of $30{ }^{\circ} \mathrm{C}$ and $20 \mathrm{MPa}, 1 \mathrm{~m} 3$ of liquid nitrogen can be vaporized into $39.5 \mathrm{~m} 3$ of high-pressure nitrogen, which can fill the annulus of $3290 \mathrm{~m}$ of $88.9 \mathrm{~mm}$ tubing and $177.8 \mathrm{~mm}$ casing.

\subsection{Risk identification of well killing management in annulus zone}

Risk identification is an important part of the safety evaluation of high-sulfur gas pressure wells, and is the premise of qualitative and quantitative evaluation.

\subsubsection{Division of well killing unit in annulus zone}

According to the principle of risk identification, ensuring science and reasonableness, and the principle of facilitating implementation evaluation, the safety management unit is divided into three units: personnel qualification unit, rule-making unit, and emergency rescue unit.

\subsubsection{Identification of safety checklist}

The biggest advantage of the safety checklist is that there is enough time to arrange for the preparation of 
experienced professionals. The evaluator records the observed problems in the prepared record form through on-site survey and measurement. In the evaluation process, the qualifications, age, experience, profession, and physical conditions of the practitioners should be taken as the sub-category of the evaluation and analysis, and then the education status, including gas field expertise, professional skills, and retraining requirements. Of course, the best management evaluation depends on the operation process. Observe whether the practitioners comply with the operating procedures and whether they are proficient. This is the focus of the analysis of the safety checklist, and it is also a direct and effective basis for discovering the existence of dangerous and harmful factors in the management. This requires that the participating evaluators have deep theoretical knowledge and rich practical experience, as well as comprehensive judgment capabilities, analytical capabilities and on-site communication capabilities.

According to the characteristics of the gas storage well, the second safety checklist is compiled. Check and analyze the rationality of the organizational structure and the adequacy of staffing. There is also the investment protection of safety expenses, whether the work injury insurance is paid in full, whether the safety expenses have been established in accordance with the requirements of the country, and whether the safety expenses have been established in accordance with the requirements of the country. In the evaluation process, attention should be paid to the integrity and effective traceability of the financial statements. In addition, it is necessary to make detailed judgments on rules and regulations, responsibility systems, and operating procedures. This is also the focus of well killing management in the high-sulfur annulus. Inspection is mainly to determine whether the rules and regulations, responsibility system, and operating procedures are effective, complete, and whether they are in compliance. The actual production needs, whether there are unrealistic requirements, should analyze the risks that exist in the critical operation process.

Finally, the third safety checklist is compiled. For example, for the high-sulfur annulus killing well, whether it has been designed by a formal and qualified design unit, and whether the construction unit and supervision unit meet the qualification requirements. At the beginning of the design, is there any safety pre-evaluation and "three simultaneous" acceptance. Whether special equipment is registered, filed, and tested in accordance with national laws and regulations. Check whether the fire-fighting facilities are accepted, and whether the acceptance is satisfied. These are the conditions that safety management must basically comply with. In short, safety management is a systematic project that runs through the entire process. In the process of safety evaluation, we must first grasp the important links and key factors to ensure the efficiency of safety evaluation.

\subsubsection{Analysis of personnel reliability}

Personnel reliability analysis can reduce the chance of human error and control the source of management error.
By analyzing the operating characteristics and operating conditions of the gas field, for example, in the case of a sulfur-containing gas field, there is a high-pressure annulus. Then, whether the preventive measures for fire, explosion, and poisoning and the use of preventive tools meet the needs of this production characteristic. Interpret the relevant operating procedures of the operators and discover the possibility of human error, so as to improve and solve the problem.

\section{In conclusion}

(1) The causes of pressure in the annulus can be divided into three categories: application of operation, temperature-induced fluid expansion and contraction, and leakage of components such as downhole tubing string and cementing cement ( integrity failure). The annulus pressure caused by the first two reasons can be eliminated by wellhead pressure relief, which is less harmful to the gas well; the annulus pressure caused by the integrity failure is more harmful and needs to be treated differently.

(2) The annulus pressure control system can avoid the situation that the annulus pressure is too high and the casing is damaged. It is very important to determine the appropriate set pressure. Too high or too low set pressure will affect the wellbore integrity of the gas well and the service life of the annulus pressure control system.

(3) The evaluator is required to be able to fully understand the annulus pressure mechanism and be very proficient in the operation process. In the identification process, we must grasp the formation, detection, prevention, and emergency hazard identification of air pressure. Point out the basis for improper management, inadequate management, etc., and put forward the causes, consequences, and possible collateral accidents.

\section{References}

1. Li Yueyang, Tian Yuanyuan, Cao Peng, etc. Screening and optimization of construction conditions for gas storage[J]. Journal of Southwest Petroleum University (Natural Science Edition), 2013,35(5): 123-129. doi: 10.3863/j.issj.issn.16745086.2013.05.017

2. Yuan Jinping, Li Gensheng, Zhuang Xiaoqian, etc. Gas injection and brine injection and well completion technology for underground salt cavern gas storage

[J] . Natural Gas Industry, 2009,29(2): 76-78.doi: 10.3787/j.issn.1000-0976.2009.02.020

3. Zhao Zhicheng, Zhu Weiyao, Shan Wenwen, etc. Research on the mechanism of salt cavern gas storage water solution cavity construction[J]. Petroleum Exploration and Development, 2003,30(5): 107109.doi: 10.3321/j.issn:1000-0747.2003.05.032

4. Jin Jianzhou, Jie Wen, Zhang Hua, et al. Liner cementing technology for Well Bai $6 \mathrm{Ku} 1$ of Dagang Bannan Gas Storage [J] Drilling Fluid and Completion Fluid, 2004,3(6): 58-61.doi:10.3969/ j.issn .1001-5620.2014.06.016

5. Liu Shuoqiong, Qi Fengzhong. Challenges and 
research directions of CNPC's cementing[J]. Petroleum Drilling Technology, 2013,41(6): 611.doi:10.3969/-j.issn. 1001-0890.2013.06.002

6. Wang Zhaohui, Chen Jun, He Xueliang, et al. Analysis of the influencing factors of the annulus pressure of the oil casing of a gas storage well. Journal of Southwest Petroleum University (Natural Science Edition)

7. Zhang Zhi, Gu Nan, Yang Hui, et al. Research on safety evaluation of annulus pressure in high-sulfur and high-yield gas wells. Drilling and production technology

8. Chen Zhengmao. Management risk and safety evaluation of killing wells in the annulus of highsulfur gas fields. Shandong Industrial Technology

9. Wang Yun, Li Wenkui. High-temperature, highpressure and high-acid gas field annulus well killing risk level discrimination model "J". Petroleum Drilling and Production Technology, 2012, 34(5): 5760.

10. Lu Junan, Liu Lei, Wang Yanmin, et al. Pressure management technology for oil casing annulus of high-pressure gas wells. Liaoning Chemical Industry 1004-0935 (2015) 03-0329-03

11. Wei Donghou, Dong Shaohua, Liang Wei. Research on the Integrity Management System of Underground Gas Storage and Related Technology Application "J". Oil and Gas Storage and Transportation, 2015, 34(2): $115-121$.

12. Yuan Guangjie, Yang Changlai, Wang Bin, et al. Analysis of the status quo of well drilling and completion technology for domestic underground gas storage "J". Natural Gas Industry, 2013, 33(02): 6164.

13. American Petroleum Institute. Technical report on equations and calculations for casing, tubing, and line pipe used as casing or tubing; and performance properties tables for casing and tubing. API TR 5C3. 2008.

14. Petroleum Drilling Engineering Professional Standardization Committee. SY/T 5724-2008 Casing string structure and strength design "S". Beijing: China Standards Press, 2008.

15. API RP 90. Annular casing pressure management for offshore wells "S". American Petroleum Institute, Washington, DC, 2006.

16. Duan S. Risk analysis method of continuous air emissions from wells with sustained casing head pressure "C".SPE 94455, 2005.

17. Zhang Zhi, Huang Yi, Li Yanjun, et al. Safety evaluation of production casing for killing wells in annulus with consideration of corrosion "J". Journal of Southwest Petroleum University (Natural Science Edition), 2014, 36(02): 171-177.

18. ISO/TS 16530-2 Well integrity-Part 2-Well integrity for the operational phase "S". Rev: ISO, 2014.

19. Norwegian Oil Industry Association and Federation of Norwegian Manufacturing Industries. NORSOK
D-010 Well integrity in drilling and well operations "S". Strandveien: Norsok, 2004.

20. Gu Xiaohong, Mu Jianmin, Shi Junsheng, et al. Diagnosis and management of annulus pressure risk in Puguang high-sulfur gas wells "J". Fault Block Oil and Gas Field, 2013, 20(5): 663-666.

21. Zhu Dajiang, Lin Yuanhua, Zou Dapeng, et al. Research on the corrosion mechanical properties of the packer rubber material for $\mathrm{CO} 2$ flooding gas injection wells "J". Petroleum Drilling Technology, 2014, 42(5): 126-130.

22. Sun Li, Fan Jianchun, Sun Yuting, et al. Research on the concept of gas well integrity and evaluation index "J". China Work Safety Science and Technology, 2015, 11(10):79-84. 